\title{
Entrevista a Débora Tajer
}

Comité de Redacción: ¿Qué aportes teóricos realizó Gilou García Reynoso que han permitido pensar la relación entre psicoanálisis y género?

Débora Tajer: Uno de los aportes más importantes de Gilou a lo que es la relación entre psicoanálisis y género es toda su teorización sobre la relación del sujeto al poder. Hay una publicación que ha hecho en la revista Postdata de Rosario ${ }^{1}$, donde se sistematizó lo que fue un coloquio sobre el duelo del Padre que se organizó cuando vino Jessica Benjamin en el año 1998 organizado por Ricardo y Marisa Rodulfo y el Foro de Psicoanálisis y Género APBA. Ella planteó ahí cosas muy interesantes en relación a cómo hay que desidentificarse de los otros primordiales introyectados por la asimetría generacional en la primera infancia, pero que el patriarcado de alguna manera hace que eso se sostenga en estadíos posteriores de la vida donde la asimetría generacional no tiene el impacto que tiene en la infancia. Es decir, que se sostiene una asimetría intrapsíquica allí donde ya la realidad no conlleva las mismas relaciones de poder. Señalaba que los procesos de desidentificación son tan importantes como los de identificación. Y que estos procesos podían llevar a la libertad, no a la del ostracismo sino una con reconocimiento del otro en una medida muy distinta a ese otro primigenio omnipotente, desmesuradamente grande en relación al niño. Otro narciso absoluto para que ingrese otro u otra para amar en el amor y en la amistad. Esto que Gilou trabajaba sirve mucho para trabajar perspectiva de género en psicoanálisis porque parte de lo que trabajamos es la interiorización psíquica de las asimetrías de poder en lo social: cómo aún en situaciones donde hay posibilidad de mayor igualación, esta introyección vía los procesos primarios de identificación que incluye contenidos de género, es un modo de incorporación temprano de la diferencia desigualada. Asimetría que hace que las mujeres, por ejemplo, nos relacionemos con los hombres suponiéndoles una hegemonía que no la tienen en muchos casos, no como sujetos de la vida, sí como portadores de blasones históricos, pero quizás no por sus posiciones subjetivas. Esto lo ha complementado Martha Rosemberg cuando dice esto de a la caza de la cabeza del Rey acéfalo. Gilou planteaba que es necesario revisar la identificación con ese otro primordial que introyecta esta asimetría para poder relacionarse con un otro par, ella decía con un otro para amar en el amor y en la amistad. Esto es fundamental para trabajar psicoanálisis y género porque parte de lo que hacemos precisamente es trabajar con la introyección de la desigualación, en el caso de las mujeres como el género devaluado y en el caso de los varones como el género hegemónico. Esto es algo que hay que poder deconstruir para tener relaciones de pares políticos, según un concepto de Ana María Fernández.

CdR: A partir de estos aportes teóricos, ¿qué reformulaciones en la teoría psicoanalítica se pueden ubicar en esta línea?

Débora: He utilizado estos aportes de Gilou y los he traido al campo de la relación entre psicoanálisis y género. Lo he trabajado en un artículo mío que se llama "Diversidad y clínica psicoanalítica", que es del libro "La diferencia desquiciada” del año 2013 de la editorial Biblos, una compilación de Ana María Fernández y Wiliam Siqueira Peres. Ahí trabajo este concepto de

\footnotetext{
${ }^{1}$ García Reinoso G. Las relaciones del sujeto al poder. Revista Posdata, Homo Sapiens editores, 1997, 27-32

2 Tajer D. "Diversidad y clínica psicoanalítica: apuntes para un debate", En "La diferencia desquiciada" Ana María Fernández y Wiliam Siqueira Peres Compiladores, 2013, Editorial Biblos-
} 
Gilou y lo traigo al campo de psicoanálisis con perspectiva de género y digo esto que mencionaba antes: es un aporte importantísimo para poder trabajar en psicoanálisis no desde una ilusión de simetría sino sabiendo que el punto de partida - por las relaciones patriarcales- es una desigualación y el punto de llegada en los trabajos clínicos nos debe poder conducir a una posición de sujetos y sujetas dando cuenta de sí y con más oportunidades de desarrollar sus posibilidades en la vida, que sería a lo que apuntaría la perspectiva de género en psicoanálisis. Es decir, sacarse los corset de género, en términos de restricciones, pero también en términos de incorporación o introyección de las asimetrías jerárquicas que el patriarcado propone.

CdR:: ¿Qué transformaciones y efectos se pueden leer en la práctica?

Débora: Estas cuestiones tienen efectos en la clínica que son maravillosos. Gilou, de hecho, era una psicoanalista de primer nivel, más bien superlativa. Doy cuenta de eso, me he analizado veinte años con ella y realmente le debo mucho y le agradezco profundamente, pero también he hablado con otras personas que se han psicoanalizado con ella y también le estamos eternamente agradecidos y agradecidas. Esto tiene un impacto en la clínica impresionante porque permite deconstruir las marcas del patriarcado en el psiquismo y en eso, en términos prácticos, Gilou ha sido una genia total. Ella ha sabido hacer mucho acerca de ésto y quienes hemos sido tocados por ella en la vida de diferentes modos -en la amistad, en la docencia, en la clínica- podemos dar cuenta de que esto permite partir aguas impresionantemente en términos de emancipación, de posicionarse en la vida, de hacerse cargo de una misma y de relacionarse con los otros. Creo que a Gilou parte de lo que le interesaba en términos clínicos era mejorar la vida con los otros, siempre con los otros, con los semejantes, con los otros íntimos y con los no tan íntimos, para ella esta era una preocupación muy importante. Por otro lado, hay otros temas de debate. Gilou no se decía a sí misma alguien con perspectiva de género, no la escuché decirse feminista. Pero sí era una persona descendiente de franceses con la Revolución Francesa incorporada ¿no?, con un grado de ciudadanía muy alto. Sin tener que darlo como consigna sino poniéndolo en acto. De hecho he tenido discusiones con ella, debates, donde ella seguía sosteniendo el concepto de diferencia sexual en psicoanálisis y la idea de dos posiciones. Seguía sosteniendo eso, incluso en algún momento yo le decía "pero Gilou, todavía eso!", entonces ella me decía "bueno, bueno, yo que sé, a lo mejor no para todos, pero para los que están en la heterosexualidad sî”, como diciendo no es universal. Es decir, ahí concedió que no todos los amores o todas las estructuraciones psíquicas deben basarse en el concepto de la diferencia sexual como organizadora de todas las diferencias. Lo que ella sí quería plantear es que en la modernidad o en ciertos sujetos que están estructurados así, eso funciona de esa manera. Lo que concedió es que no necesariamente esto deba ser un universal, tanto en la estructuración como único modo, y tampoco en los modos deseantes. Con lo cual se podría decir que en términos conceptuales habría algunas cuestiones de lo femenino y lo masculino que quienes hacemos género presentamos algunas diferencias con cómo ella se posicionaba en términos teóricos. Pero en términos clínicos, su clínica era de avanzada, sumamente de avanzada. Me parece que para una feminista como es mi caso y para muchos militantes en general - porque he visto gente muy valiosa y muy conocida como compañeros y compañeras "de diván” en las entradas y en las salidas- pensamos que ha sido alguien que ha podido colaborar muchísimo para que podamos hacer nuestras vidas y hacer con otros. Otro tema interesante -que eso se lo escuché una vez en una mesa hace varios años, no sé cuántos años se conmemoraban de Plataforma y ella era la única mujer en la mesa- fue cuando planteó el tema de ser mujer psicoanalista. Era un tema interesante que ella planteaba desde entonces, cuando hicieron la ruptura en la A.P.A. en los setenta, que aún en ese momento 
era imperdonable para incluso los psicoanalistas de avanzada y rupturistas no poder aceptar a las mujeres psicoanalistas como mujeres. De alguna manera ella parafraseaba algo que decía Freud cuando las psicoanalistas mujeres le decían "pero profesor, usted dice que las mujeres no aportamos a la cultura", entonces él les dijo "ustedes no, las otras", como mujeres excepcionales, no como mujeres. Entonces a Gilou le importaba mucho esto y decía algo así como que era muy mal tolerado en los ambientes psicoanalíticos, incluso en los de avanzada y de vanguardia, soportar - esa sería la palabra- que una mujer es una mujer. Que una mujer poderosa o una mujer con desarrollo intelectual no es un varón con faldas. Este tema de la masculinización, no desde las propias mujeres sino desde la mirada de los varones sobre las mujeres poderosas, las mujeres emprendedoras o las mujeres brillantes a nivel intelectual. También decía algo de malsoportar el tiempo necesario para la maternidad aun cuando alguien quiere seguir desarrollándose intelectualmente y laboralmente, que había algo de eso que era muy difícil de sostener para los hombres, y ella lo decía así abiertamente. Esto es interesante porque también es algo que está en Marie Langer, cuando le agradece a su marido, algo muy interesante que es haber podido acompañarla y sostenerla en el tiempo donde ella necesitaba sostener la maternidad. Algo de esto también decía Gilou, me parece que allí hay una coincidencia entre ambas maestras.

$C d R$ : ¿Podrías ampliar en relación al debate sobre la diferencia sexual en psicoanálisis como organizadora de todas las diferencias?

Débora: Gilou tenía la concepción clásica de esto que es, tal como se dice en psicoanálisis -digamos en la versión lacaniana fundamentalmente-, que la diferencia sexual es la organizadora de todas las diferencias. Desde psicoanálisis y género no lo pensamos así. Pensamos que el simbólico patriarcal y heteronormativo establece un binarismo y dos lugares, y hay una definición apriori de que esto es el modo de organización de lo simbólico, pero hay otros modos de organizaciones posibles. Sostenemos que la diferencia sexual es una entre otras diferencias, no la que organiza las otras diferencias, y esto también en relación a los deseos por fuera que no están convocados por la diferencia sexual. Lo que no quiere decir que la desconozcan, sino que no están causados por la misma. 